\title{
AVALIAÇÃO DO SOLO DA ILHA DOS ARVOREDOS, SP - BRASIL *
}

\author{
Willy Ank de Morais ${ }^{1}$ \\ Marcio de Morais Tavares ${ }^{2}$ \\ Erika Elis $\mathrm{Kuo}^{3}$ \\ Aldo Arouca ${ }^{4}$
}

\section{Resumo}

Pontos estratégicos de solos foram analisados com o objetivo de estudar a possível contaminação de água pluvial, por difusividade, mantidas em reservatórios existentes na Ilha dos Arvoredos, localizada no Guarujá, litoral de São Paulo, Brasil. Iniciou-se o procedimento com a preparação das amostras (homogeneização e quarteamento), seguida das análises físicas (granulometria e umidade). A caracterização foi realizada por espectrometria de fluorescência de Raio-X e por espectrometria de absorção atômica. As concentrações de enxofre foram quantificadas por forno de combustão e as cinzas e matéria volátil por TGA (Analisador Termogravimétrico). As análises realizadas em Raio $-\mathrm{X}$ mostraram composição química de solo argiloso com altas concentrações de $\mathrm{SiO}_{2}$ e $\mathrm{Al}_{2} \mathrm{O}_{3}$ e as realizadas no equipamento de combustão mostraram concentrações de enxofre menores que $0,03 \%$. Os resultados se apresentaram negativos para metais pesados ou outro tipo de elemento que poderia comprometer a potabilidade das águas contidas nos reservatórios.

Palavras-chave: Solo, Raio-X, Absorção Atômica, Termogravimetria.

\section{SOIL EVALUATION OF ARVOREDOS ISLAND, SP - BRAZIL}

\begin{abstract}
Strategic points of soils were analyzed in order to study the possible contamination of rainwater by diffusivity, kept in existing reservoirs on the island of Arvoredos, located in Guaruja, coast of São Paulo, Brazil. The procedure began with preparation of the samples (homogenization and quartering), followed by physical analysis (particle size and moisture). Characterization was performed by fluorescence spectrometry X-ray and by atomic absorption spectrometry. Sulfur concentrations were quantified by combustion furnace and ash and volatile matter by TGA (Thermogravimetric Analyzer). The analyzes in -X-ray showed chemical composition of clay soil with high $\mathrm{SiO}_{2}$ and $\mathrm{Al}_{2} \mathrm{O}_{3}$ concentrations and those in the combustion equipment shown sulfur concentrations lower than $0.03 \%$. The results were negative for heavy metals or other element that could compromise the potability of the water contained in the tanks.
\end{abstract}

Keywords: Soil, X-ray, Atomic Absorption, Thermogravimetry.

1 Doutorando, Mestre, Engenheiro e Técnico em Metalurgia e Materiais, Sócio-Diretor da Willy Ank Soluções Metal-Mecânicas, Professor Mestre da UNAERP-Guarujá e Professor Adjunto da Universidade Santa Cecília (UNISANTA), Santos, SP, Brasil (wmorais@unaerp.br).

2 Engenheiro Químico, Mestre em Engenharia Mecânica, Doutorando em Engenharia Química, Coord. do Curso de Eng. Civil e de pós graduação em Eng. de Segurança do Trabalho da UNAERP, Guarujá, SP, Brasil (mtavares@unaerp.br).

3 Graduanda em Engenharia Civil, UNAERP, Guarujá, SP, Brasil (erikakuo@hotmail.com).

4 Mestre, Engenheiro Ambiental, Assessor Ambiental do (DER-SP), docente de Engenharia Civil, UNAERP, Guarujá, SP, Brasil (aarouca@unaerp.br). 


\section{INTRODUÇÃO}

A llha dos Arvoredos possui uma área de 36 mil metros quadrados e está localizada a 1,6 km da praia de Pernambuco no Município do Guarujá, litoral central do Estado de São Paulo, Brasil, conforme ilustrado pela Figura 1. Ausente de mananciais esta ilha se tornou um laboratório a céu aberto, leito de um grande número de pesquisas que visam à sustentabilidade em água e energia. Fernando Eduardo Lee, engenheiro brasileiro e neto de norte-americanos, desenvolveu e implementou inúmeras pesquisas em sustentabilidade nesta ilha ao longo de mais de quarenta anos nas áreas de energias alternativas, reaproveitamento de biomassa e ecologia locais [1]. Lá foram instaladas as primeiras placas de energia solar do Brasil, além hélices de energia eólica e um sistema de captação, armazenagem, aquecimento e filtragem de água da chuva. Atualmente a ilha é gerida pela UNAERP e pela Fundação Lee, que foi criada pelo engenheiro antes de sua morte.

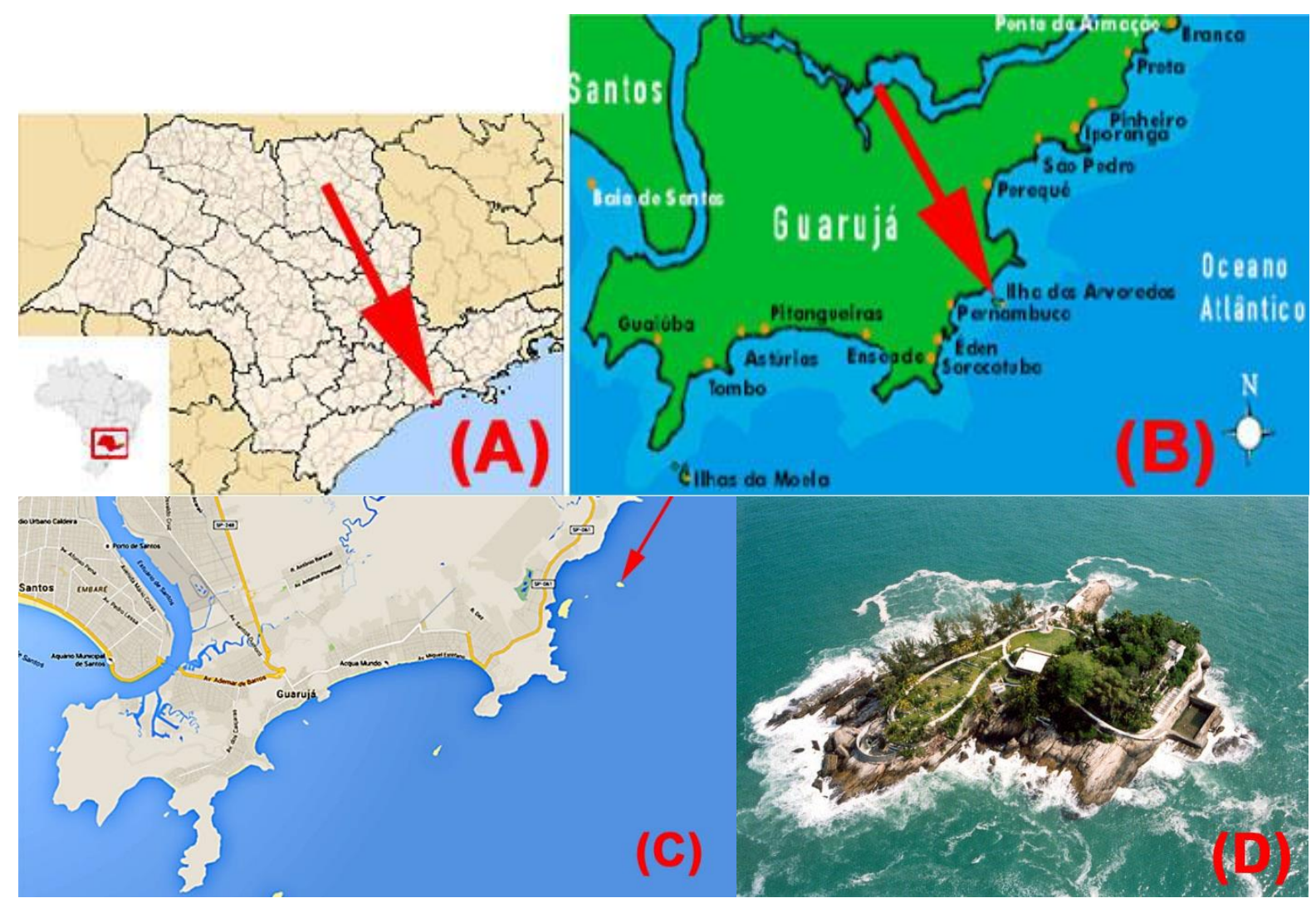

Figura 1. Localização da llha dos Arvoredos, no litoral de São Paulo [2].

Dentre os diversos projetos desenvolvidos, a captação de água pluvial recebeu atenção especial e foi aplicada tanto no telhado da Casa Principal como em pontos estratégicos da ilha, nos quais foram construídos reservatórios para armazenar e permitir o uso deste recurso ao longo de todo o ano [1]. Existem diversas pesquisas em andamento visando a conservação da infraestrutura e o desgaste do concreto das construções devido à influência dos elementos químicos presentes na água do mar e pelas ondas e ventos [3].

Fernando Lee desenvolveu uma técnica na área de Geologia através do plantio da espécie Neumarica caerulea conhecida popularmente como íris-da-praia, nos trechos de grande declividade da ilha e com isso conter as erosões e consequente 
perda da fina camada de solo característico deste frágil ecossistema. Por tratar-se de um ambiente insular, conforme ilustrado na Figura 2, a qualidade do solo nos arredores dos reservatórios de água pluvial tornou-se um ícone de grande importância [4]. A investigação estrutural do solo desta ilha nos arredores destes reservatórios para verificação de possíveis contaminações destas águas constitui o objetivo deste trabalho.

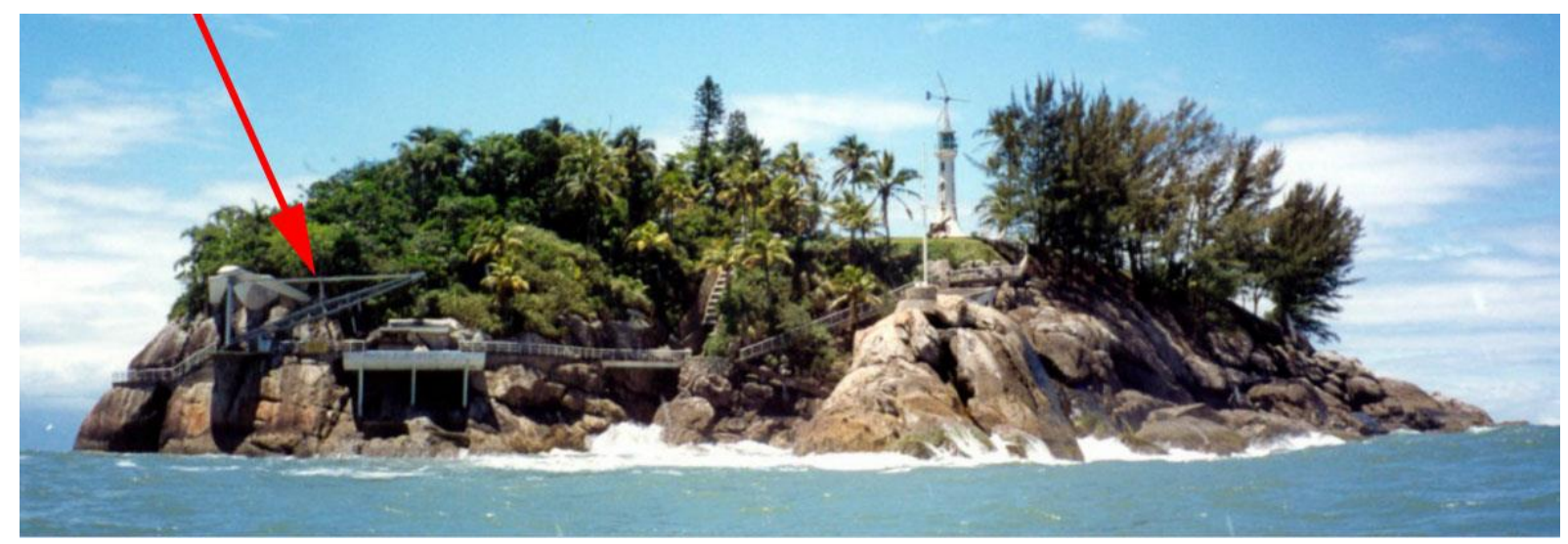

Figura 2. Vista geral da llha dos Arvoredos. O guindaste no extremo esquerdo da foto e destacado pela seta à esquerda é o único meio de acesso à ilha [3].

\section{MATERIAIS E MÉTODOS}

\subsection{Amostragem}

Foram analisadas amostras de água obtidas de reservatórios que armazenam água pluvial que abastece a casa principal e o alojamento da ilha. As amostras foram coletadas em três pontos estratégicos, em volta do tanque 01 e do tanque 02 , disponíveis na llha e ilustrados na Figura 3. A profundidade de coleta foi de $500 \mathrm{~mm}$, conforme recomendado pela literatura [5].

Também foi realizada uma amostragem próxima ao chafariz, que possui uma estrutura que direciona a água para um terceiro reservatório de água pluvial, sob a forma de uma cascata. A amostra retirada deste local foi denominada amostra da cascata.

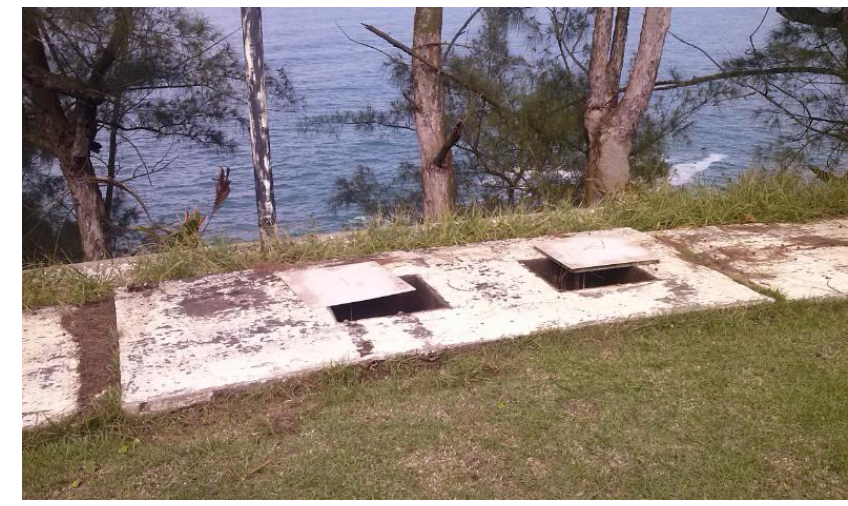

(A)

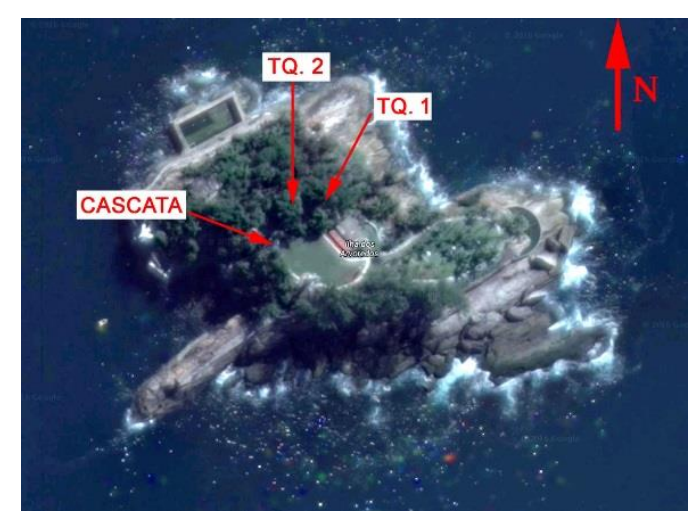

(B)

Figura 3. (A) Aspecto dos Reservatórios de água pluvial sob o solo argiloso da ilha. (B) Localização relativa dos reservatórios em relação à llha. 


\subsection{Preparação das Amostras}

As amostras foram preparadas pelo método de acordo com a NBR ISO 3082 [6]. O material foi homogeneizado ao passar três vezes em um divisor de rifle, ilustrado na Figura 4, reservando uma parte para análise e a outra para amostra testemunha [7].

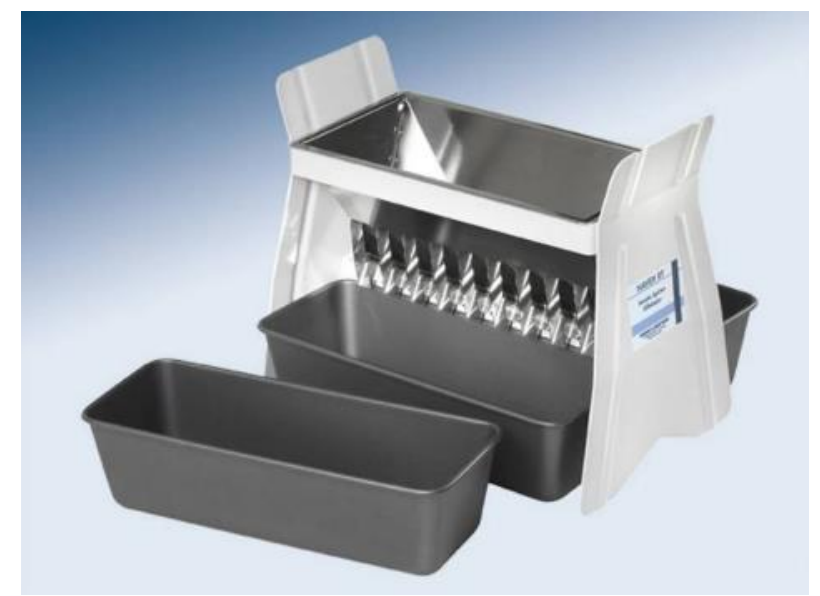

Figura 4. Divisor de rifle.

O rejeito da homogeneização foi empregado para ambientar os equipamentos empregados na análise: a mesa, a pá e a cruzeta. Essa última foi empregada para dividir a amostra final em quatro partes, como ilustrado na Figura 5:

- as partes $\mathrm{A}$ e $\mathrm{B}$ foram empregadas para análise química;

- a parte $C$ foi empregada para análise granulométrica e determinação da umidade;

- a parte $D$ foi orientada para fazer ambientação.

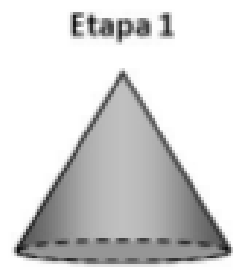

Etapa 2

Etapa 3
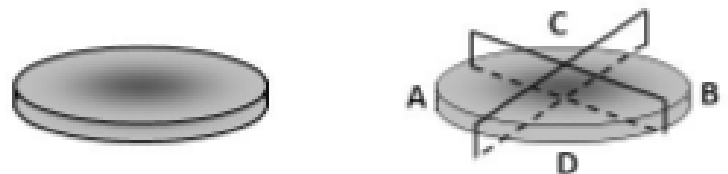

Figura 5. Esquema de divisão por cone e quarteamento.

\subsection{Ensaios Físicos (umidade e granulometria)}

Efetuou-se a retirada e determinação da umidade pesando-se a amostra antes e depois a passagem por uma estufa a $100+/-5^{\circ} \mathrm{C}$. Em seguida montou-se a série de peneiras em ordem crescente começando pelo fundo, despejou-se a amostra e iniciou-se 0 peneiramento com movimentos estáveis $e$ ininterruptos por aproximadamente 5 minutos. Pesou-se o material retido em cada peneira e anotouse individualmente o peso conforme procedimento de literatura [7]. 
A determinação do tamanho médio das partículas (em milímetros) foi obtido de acordo com a Equação 1:

$$
\mathrm{TM}=\Sigma \mathrm{A} \times(\mathrm{B} / 200)
$$

Na qual: TM é ó tamanho médio das partículas (em mm);

A é o percentual retido em cada fração;

B é a soma da malha da peneira atual com a malha da peneira imediatamente superior

\subsection{Caracterização}

Os equipamentos empregados conseguem efetivamente detectar e quantificar elementos a partir do Flúor. Sendo assim, todos os elementos de número atômico inferior na tabela periódica não são quantificados. Por isso, sua composição não normalizada não resulta em $100 \%$ e é uma técnica comum na química realizar um levantamento do material perdido por calcinação (PPC), para dar o fechamento da análise [5-7].

Após determinar a Perda ao Fogo por Calcinação (PPC), efetuou-se a pulverização e briquetagem das amostras e iniciaram-se as análises utilizando o espectrômetro de fluorescência de Raio-X modelo ARL 72000 S, devidamente calibrado e aferido, conforme comprovado em trabalhos anteriores $[8,9]$. PPC é um termo técnico da química. É uma análise de termogravimetria que quantifica a massa de matéria volátil contida na amostra. A amostra pesada, foi inserida em mufla a $1000^{\circ} \mathrm{C}+/-5^{\circ} \mathrm{C}$ por uma hora em cadinho de platina, mostrado na Figura 6. Após esfriada a amostra, pesa-se e, com os valores de massa final e inicial, calcula-se a PPC ou PF (perda ao fogo).

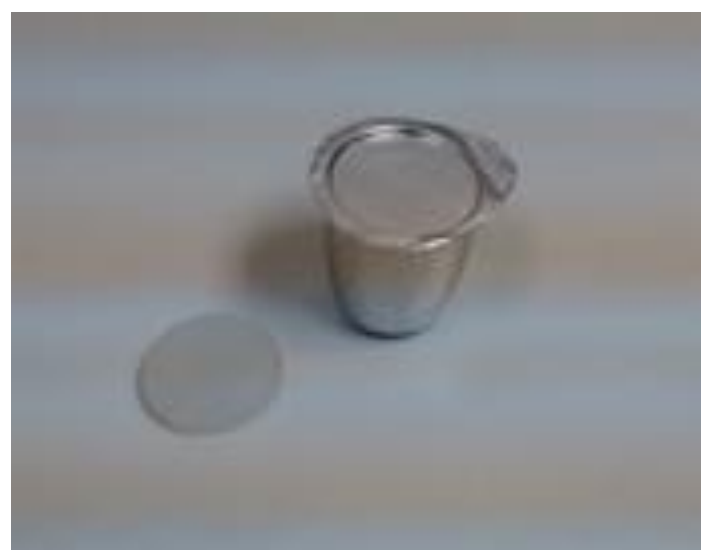

Figura 6. Cadinho de platina para fusão de amostra.

Álcalis e Manganês foram analisados pelo método da espectrometria de absorção atômica, preparadas pela técnica de fusão utilizando tetraborato de lítio $\left(\mathrm{Li}_{2} \mathrm{~B}_{4} \mathrm{O}_{7}\right)$ como fundente em máquina de fusão. Uma massa de10mg de pérolas, produto obtido da fusão da amostra em mufla, foram retiradas do cadinho de platina (Fig. 6) e dissolvidas em $\mathrm{HCl}$ em uma concentração de 1:1. As soluções foram posteriormente diluídas em balões volumétricos de $250 \mathrm{~mL}$. Este procedimento garante uma maior acuidade nos resultados, já que os valores percentuais (ou em ppms - partes por milhão) encontrados nesta solução são 250 maiores do que os 
reais. Esta análise empregou um analisador de absorção atômica modelo Spectra AA da marca Varian, apresentado na Figura 7.

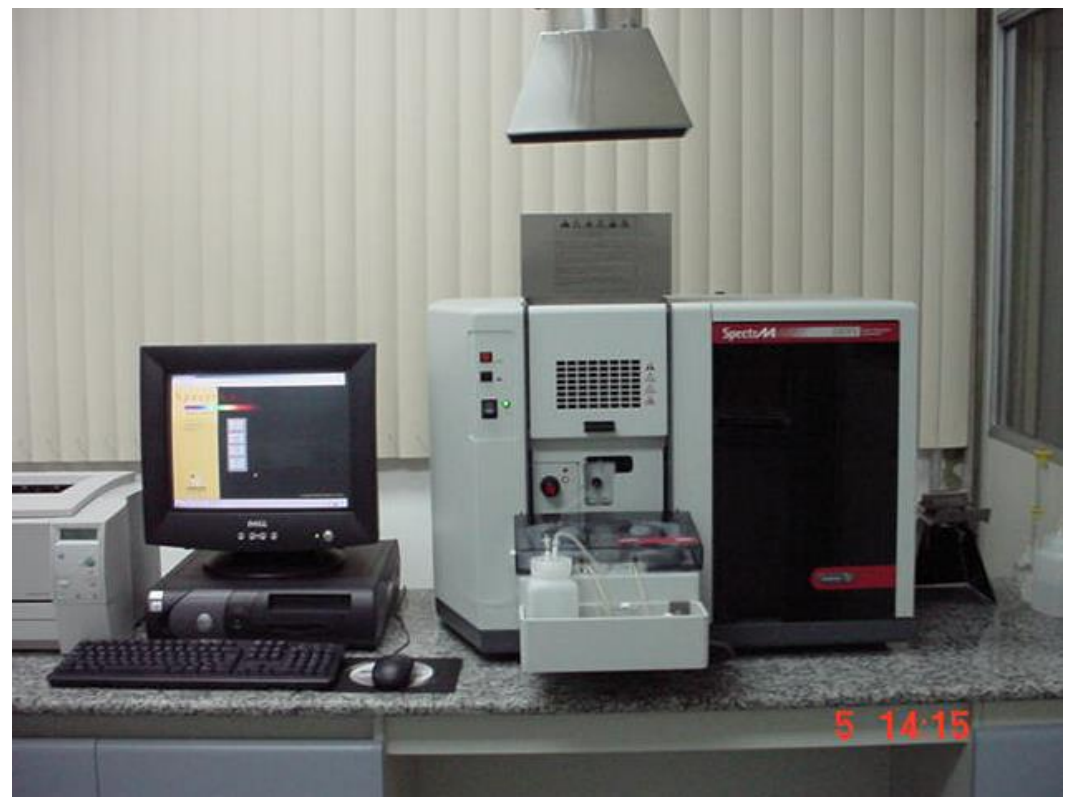

Figura 7. Espectrômetro de absorção atômica Spectra AA da Varian.

As concentrações de enxofre foram determinadas através do equipamento S-144 DR da Leco. A Umidade aderente, cinza e matéria volátil foram quantificadas através de um equipamento da Leco, modelo TGA 701. Todas as amostras foram pesadas com precisão de 4 casas decimais após a vírgula (ponto decimal) por uma balança analítica laboratorial, ilustrada na Figura 8.

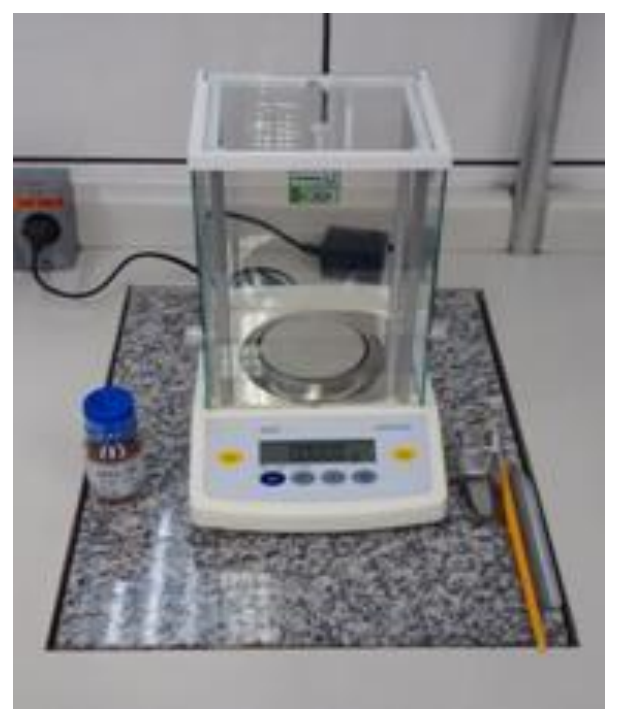

Figura 8. Balança analítica com precisão de 4 casas decimais.

Os resultados das análises serão comparados com os dados oferecidos pela Portaria MS-2914/2011 (padrões de potabilidade da água) [10], na qual as concentrações máximas permitidas de elementos químicos presentes na água, estão no descritas no anexo $\mathrm{X}$ e reproduzidas na Figura 9. 
ANEXO X

\begin{tabular}{|c|c|c|c|}
\hline Alumínio & $7429-90-5$ & $\mathrm{mgl}$ & 0.2 \\
\hline Amonla (como NH3) & $7664-41-1$ & $\mathrm{mg} / \mathrm{L}$ & 1,5 \\
\hline Cloreto & $16887-00-6$ & $\mathrm{mg} / \mathrm{L}$ & 250 \\
\hline 1,2 diclorobenzeno & $95-50-1$ & $\mathrm{mg} / \mathrm{L}$ & 0,01 \\
\hline 1,4 diclorobenzeno & $106-46-7$ & $\mathrm{mg} / \mathrm{L}$ & 0,03 \\
\hline Dureza total & & $\mathrm{mgh}$ & 500 \\
\hline Etilbenzeno & $100-41-4$ & $\mathrm{mg} / \mathrm{L}$ & 0,2 \\
\hline Manganês & $7439-96-5$ & $\mathrm{mg} / \mathrm{L}$ & 0,1 \\
\hline Monociorowenzeno & 108-90-7 & $\mathrm{mg} / \mathrm{L}$ & 0,12 \\
\hline Sódio & $7440-23-5$ & $\mathrm{mg} / \mathrm{L}$ & 200 \\
\hline solidos dissolvidos totals & & $\mathrm{mg} / \mathrm{L}$ & 1000 \\
\hline Sulfato & $14808-79-8$ & $\mathrm{mg} / \mathrm{L}$ & 250 \\
\hline Sulfeto de hidrogênio & $7783-06-4$ & $\mathrm{mgh}$ & 0,1 \\
\hline Surfactantes (como LAS) & & $\mathrm{mg} / \mathrm{L}$ & 0,5 \\
\hline
\end{tabular}

NOTAS:

(1) Valor máximo permitido.

(2) Unidade Hazen (mgPt-Co/L)

(3) Intensidade máxima de percepção para qualquer característica de gosto e odor com exceção do cloro livre, nesse caso por ser uma característica desejável em água tratada.

(4) Unidade de turbidez.

Figura 9. Limites de concentrações máximas permissíveis de elementos químicos presentes na água, conforme portaria do Ministério da Saúde de 2011 [10].

\section{RESULTADOS E DISCUSSÃO}

Os ensaios físicos, apresentados no gráfico da Figura 10, apresentaram resultados médios de umidade de:

- $12,05 \%$ para os três pontos do tanque 01 ;.

- $13,47 \%$ para os três pontos do tanque 02 ;

- $14,6 \%$ para a amostra retirada da cascata.

Tamanho médio das partículas e umidade do solo da ilha dos Arvoredos

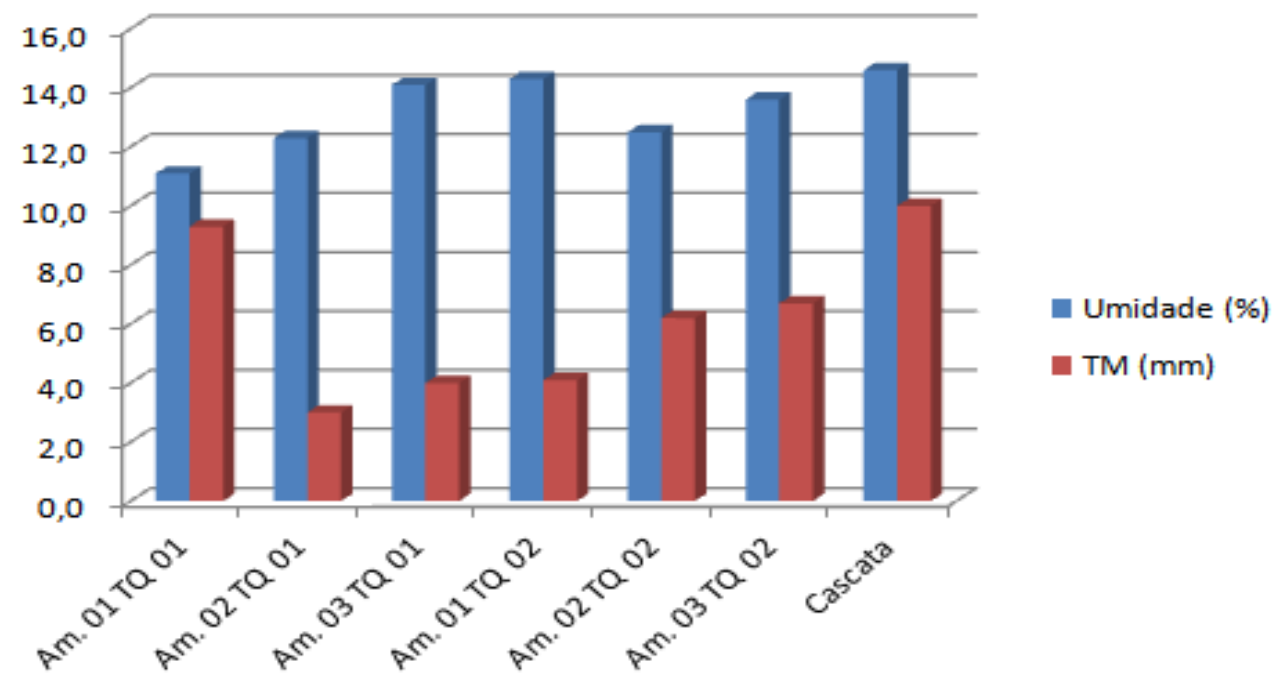

Figura 10. Resultados de umidade e TM do solo da llha dos Arvoredos. 
Os ensaios granulométricos apresentaram resultados médios de TM (tamanho médio das partículas) de:

- $\quad 5,43 \mathrm{~mm}$ para os pontos do tanque 01 ;

- 5,7 mm para os pontos do tanque $02 \mathrm{e}$

- $10,0 \mathrm{~mm}$ para a cascata.

As análises realizadas em Raio-X detectaram altas concentrações de sílica $\left(\mathrm{SiO}_{2}\right)$ e alumina $\left(\mathrm{Al}_{2} \mathrm{O}_{3}\right)$, fornecendo às amostras características de solo argiloso com presença de aluminossilicatos. O teor de ferro total apresentou concentrações médias de 3,0\%, o que é comum para este tipo de solo. Houve indicações normais de óxido de potássio $\left(\mathrm{K}_{2} \mathrm{O}\right)$, com uma concentração média de 2,15\%. Obtiveram-se baixas concentrações de $\mathrm{MgO}$ e $\mathrm{CaO}$. A Tabela 1 apresenta as composições obtidas das amostras recolhidas na llha.

Tabela 1. Composição química das amostras de solo (\%) obtidas pelos vários métodos descritos neste trabalho.

\begin{tabular}{ccccccccccccc}
\hline Ponto & PPC $^{*}$ & $\mathbf{S i O}_{2}$ & $\mathbf{A l}_{2} \mathbf{O}_{3}$ & $\mathbf{F e}$ & $\mathbf{N a}$ & $\mathbf{K}_{2} \mathbf{O}$ & $\mathbf{Z n}$ & $\mathbf{C a O}$ & $\mathbf{M g O}$ & $\mathbf{M n}$ & $\mathbf{C z}^{* *}$ & $\mathbf{M V}$ \\
\hline 01 TQ 01 & 5,42 & 72,59 & 14,64 & 3,94 & 0,015 & 2,07 & 0,002 & 0,17 & 1,06 & 0,016 & 93,13 & 6,87 \\
\hline 02 TQ 01 & 7,38 & 73,32 & 13,15 & 2,79 & 0,014 & 2,16 & 0,001 & 0,14 & 0,95 & 0,015 & 90,79 & 7,78 \\
\hline 03 TQ 01 & 9,34 & 71,84 & 12,98 & 2,62 & 0,010 & 2,06 & 0,002 & 0,15 & 0,90 & 0,016 & 89,66 & 7,85 \\
\hline 01 TQ 02 & 10,20 & 71,26 & 11,78 & 3,99 & 0,013 & 1,62 & 0,002 & 0,22 & 0,82 & 0,025 & 90,42 & 8,89 \\
\hline 02 TQ 02 & 11,30 & 69,87 & 12,38 & 2,93 & 0,012 & 2,13 & 0,002 & 0,31 & 0,97 & 0,024 & 88,79 & 9,97 \\
\hline 03 TQ 02 & 9,97 & 72,49 & 11,63 & 2,24 & 0,011 & 2,39 & 0,001 & 0,26 & 0,91 & 0,026 & 90,55 & 9,36 \\
\hline Cascata & 8,26 & 74,48 & 11,99 & 2,52 & 0,028 & 2,65 & 0,001 & 0,16 & 0,83 & 0,007 & 92,38 & 7,41 \\
\hline
\end{tabular}

${ }^{*} P P C-$ Perda Por Calcinação ${ }^{* *} \mathrm{Cz}-$ Cinzas.

As concentrações de $\mathrm{Mn}, \mathrm{Zn}$ e $\mathrm{Na}$ foram determinadas por espectrometria de absorção atômica e apresentaram teores baixos e estáveis para Mn e Zn [8]. No caso do sódio, as concentrações médias obtidas foram:

- 0,4358ppm para as amostras do tanque 01 (equivalente a 108,95ppm ou $0,011 \%$ Na no material recolhido);

- 0,4019ppm para as amostras do tanque 02 (equivalente a 100,48ppm ou $0,010 \%$ Na no material recolhido) e

- 0,8379ppm para as amostras da cascata (equivalente a 209,48ppm ou $0,021 \%$ Na no material recolhido).

Uma diferença significativa duas vezes maior para a amostra da cascata, conforme ilustra a curva de absorbância da Figura 11.

Os resultados de PPC do tanque 01 apresentaram uma diferença na média de 3,11 para menos em relação ao tanque 02 e $0,9 \%$ em relação ao solo da cascata, indicando a presença de óxidos em maiores concentrações nesta amostra do tanque 01 em relação aos demais pontos amostrados. 


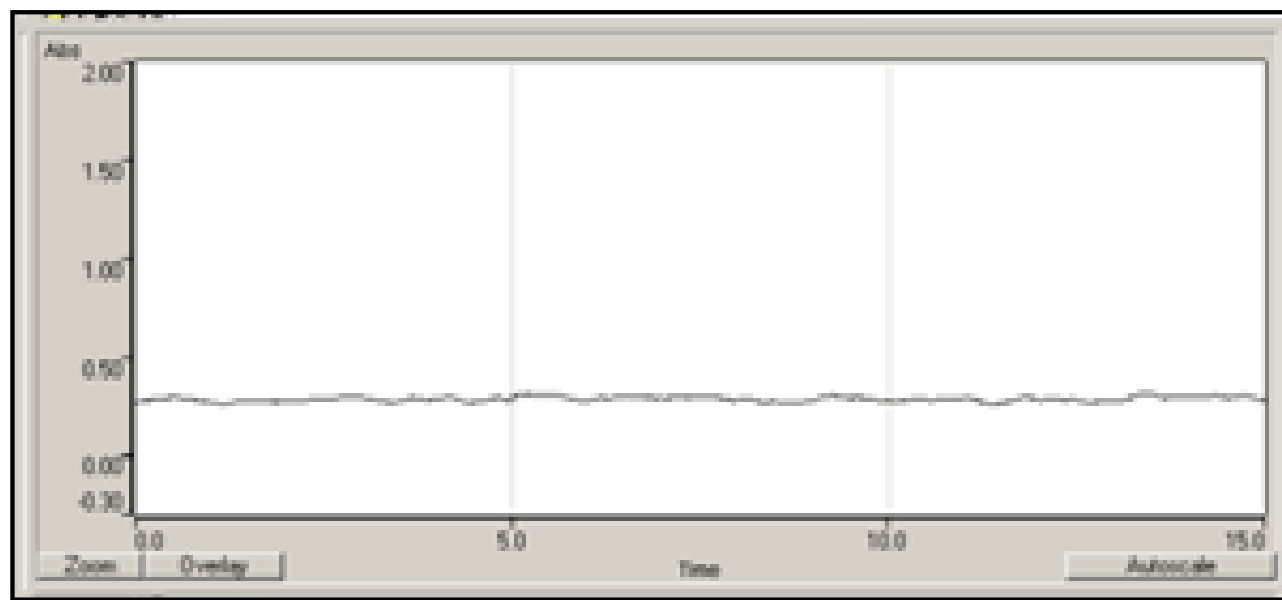

Tanque 01

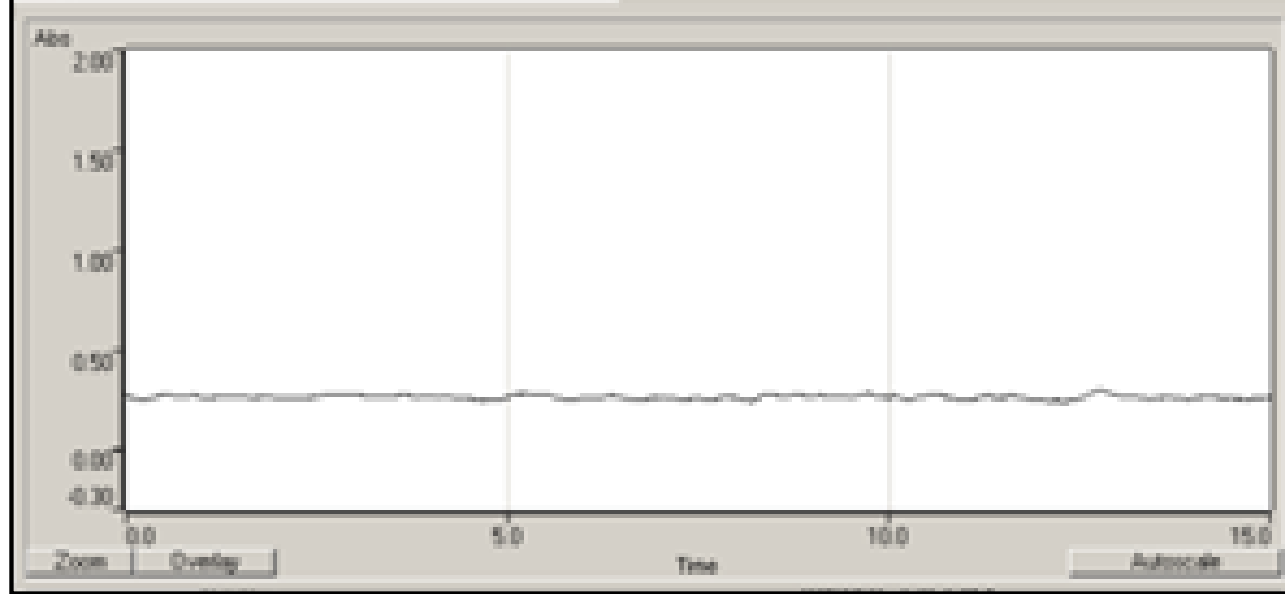

Tanque 02

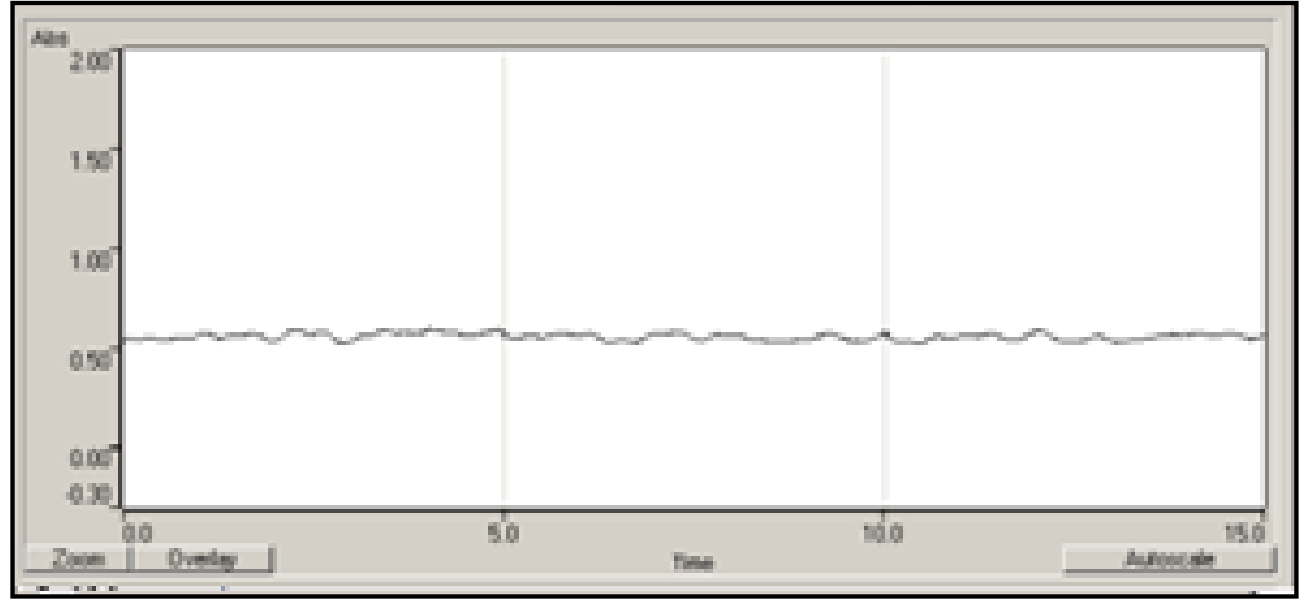

Cascata

Figura 11. Absorbância de Sódio para as amostras retiradas do llha dos Arvoredos.

As análises de enxofre realizadas em forno de combustão, conforme ilustradas pelos gráficos da Figura 12, apresentaram baixos teores deste elemento:

- 0,006 a $0,013 \%$ no tanque 01 ;

- 0,019 a $0,025 \%$ no tanque $02 \mathrm{e}$

- $0,017 \%$ na amostra da cascata. 


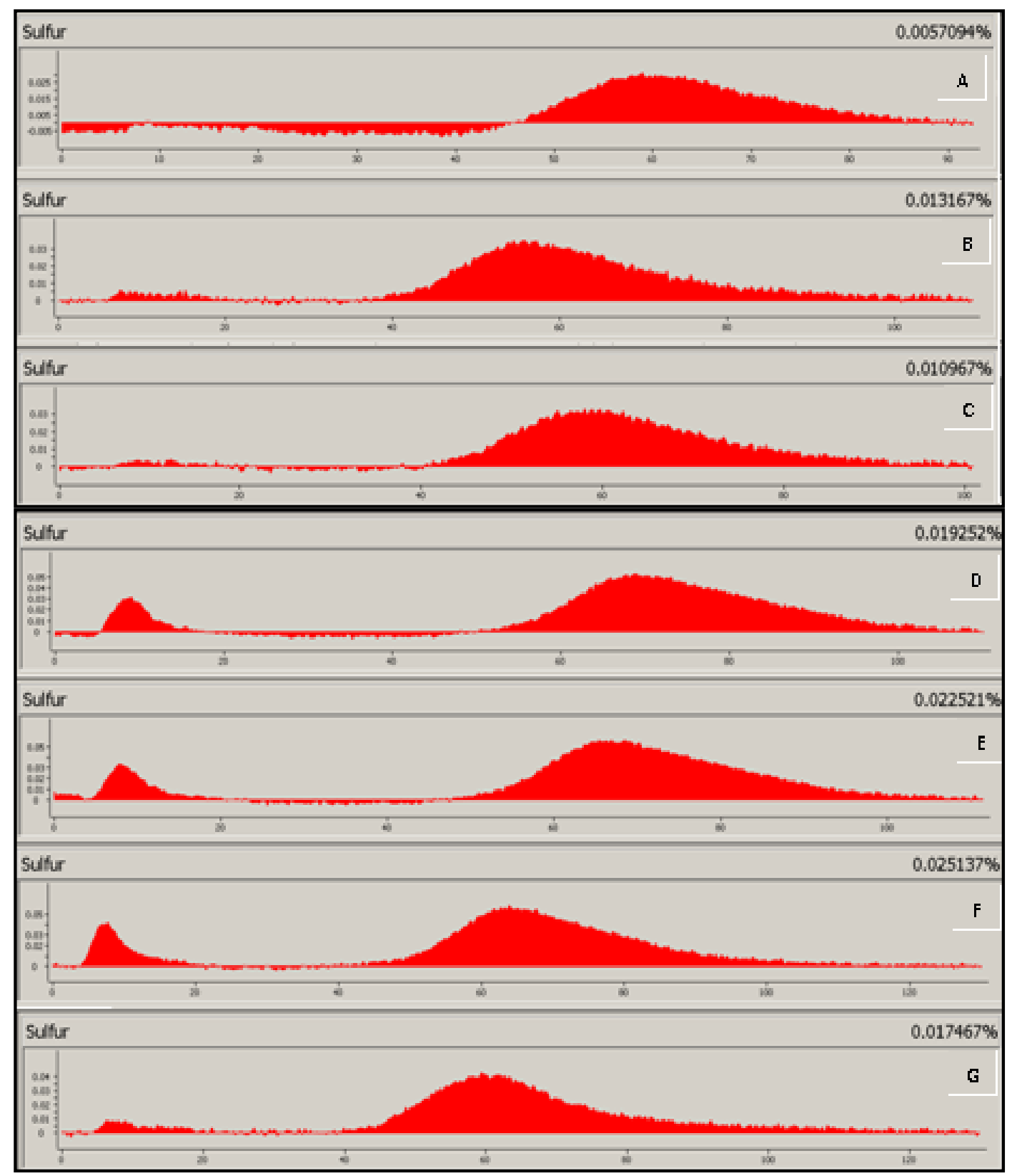

Figura 11. Curvas de concentrações de enxofre obtidas em forno de combustão para: A) Am. $01 \mathrm{TQ}$ 01; B) Am. 02 TQ 01; C) Am. 03 TQ 01; D) Am. 01 TQ 02; E) Am. 02 Tq 02; F) Am. 03 TQ 02 e G) Cascata.

Por termogravimetria determinaram-se os teores de cinza, sendo que os resultados médios foram de $90,82 \%$. Também foi possível determinar os teores de matéria volátil presentes nas amostras, sendo que os resultados médios do tanque 01 não apresentaram diferença significativa em relação ao ponto da cascata e foram $2 \%$ menor que os pontos do tanque 02 . Isto indicou que no solo adjacente ao tanque 02 houve maior concentração de material orgânico em relação aos demais pontos em estudo.

\section{CONCLUSÃO}

Os dados provenientes das análises químicas permitiram caracterizar o solo da llha dos Arvoredos como argiloso, com presença de aluminossilicatos e fragmentos de 
quartzito em todos os pontos estudados. Com base nos resultados obtidos foi possível afirmar que não há risco de contaminação inorgânica do solo adjacente a dois reservatórios (tanque 01 e tanque 02 ), os quais foram escolhidos como objeto de estudo por serem utilizados para armazenamento de água potável. Apesar dos resultados serem negativos a concentrações significativas de metais, destaca-se que no local onde há percolação de água pluvial para um terceiro reservatório (ponto da cascata), houve um aumento significativo na concentração de sódio devido à utilização deste local, em épocas remotas, para higienização de animais com água do mar.

\section{REFERÊNCIAS}

[1] LEE, F. ;SABOYA, E. O Senhor da Ilha. Santos: Editora UNISANTA, 1999.

[2] TV TRIBUNA. Ilha se transforma em laboratório natural em Guarujá, SP. Rede Globo (Portal G1.com). [acesso em: 24 jun. 2016] Disponível em: http://g1.globo.com/sp/santosregiao/noticia/2012/07/ilha-se-transforma-em-laboratorio-natural-em-guaruja-sp.html.

[3] FUNDAÇÃO FERNANDO LEE. Projetos. [acesso em: 24 jun. 2016]. Disponível em: http://www.fundacaofernandolee.org/projetos.

[4] CHAVES, I. B.; FRANCISCO, P. R. M.; LIMA, E. R. V.. Classificação das terras para mecanização agrícola e sua aplicação para o estado da Paraíba. In: Reunião Brasileira de Manejo e Conservação do Solo e da Água, 18, Teresina, 2010. Anais...Teresina: SBCS, 2010.

[5] Francisco, P. R. M. Classificação e mapeamento das terras para mecanização do Estado da Paraíba utilizando sistemas de informações geográficas. Areia: UFPB, 2010. $122 f$. Dissertação (Mestrado em Manejo de Solo e Água).

[6] ABNT NBR ISO 3082:2011. Minérios de ferro - Procedimentos de amostragem e preparação de amostras, ASSOCIAÇÃO BRASILEIRA DE NORMAS TÉCNICAS, 2011.

[7] Francisco, P. R. M.; Chaves, I. de B.; Lima, E. R. V. de. Mapeamento das terras para mecanização agrícola - Estado da Paraíba. Revista Brasileira de Geografia Física, v.5, n.2, p.233-249, 2012.

[8] Tavares, M.M; Dantas, P.R.S.; Carvalho, N.F; Pereira, S.F; Novo método para determinação de ferro total em minério de ferro por via úmida; Congresso Técnico Científico da Engenharia e da Agronomia - CONTECC 2014.

[9] Tavares, M.M; Dantas, P.R.S; Silva, H.S.; Morais, W. A.; Análise comparativa entre dois métodos de obtenção de sílica e alumina em minério de ferro; ABM Week, 2015.

[10] MINISTÉRIO DA SAÚDE. Portaria № 2.914: "Procedimentos de controle e de vigilância da qualidade da água para consumo humano e seu padrão de potabilidade", 12 de dezembro de 2011. [acesso em 24 jun. 206]. Disponível em http://bvsms.saude.gov.br/bvs/saudelegis/gm/2011/prt2914_12_12_2011.html. 